\title{
Identification and Prioritize Improvement of Accident-Prone Locations Between Srikakulam to Chilakapalem Junction- A Research
}

\author{
K.S.B. Prasad, K. Gayatri
}

\begin{abstract}
The factual investigation of accident is yielded out occasionally at grave areas or street extend which will touch base at appropriate measures to viably diminish accident rates. It is the measure (or gauges) of the number and seriousness of accidents. Thinking about the significance of point, distinguishing the reasons for street accidents has turned into the principle plan to decrease the harm brought about by automobiles collisions. So, study was carried to know how to reduce accidents by reducing the accident causing problems on NH16 from Srikakulam to Chilakapalem statistically to improve the accident locations based on priority wise.
\end{abstract}

\section{INTRODUCTION}

There are a lot of vehicles driving on the roadway every day, and traffic accidents could happen at any time anywhere[1]. The data identifying with car crashes and unfortunate casualties speaks to a fundamental device to control and distinguish security issues in transport, to recognize need activity regions and to assess the adequacy of the measures used to improve security. The issue of giving safe travel out and about system inside the urban and rural one of the major standards overseeing the building, traffic and transportation arranging[3]. Almost 3,500 individuals died on the world's streets each day Tens of a large number of individuals are harmed or impaired each year. Youngsters, people on foot, cyclists and the old are among the most defenceless of street clients. $90 \%$ road accidents occurred due to driver's careless ness like over speed, rash driving, drink and driving .in some cases due to skidding of vehicles were seen, due to very less maintenance of roads[3]

Route map:

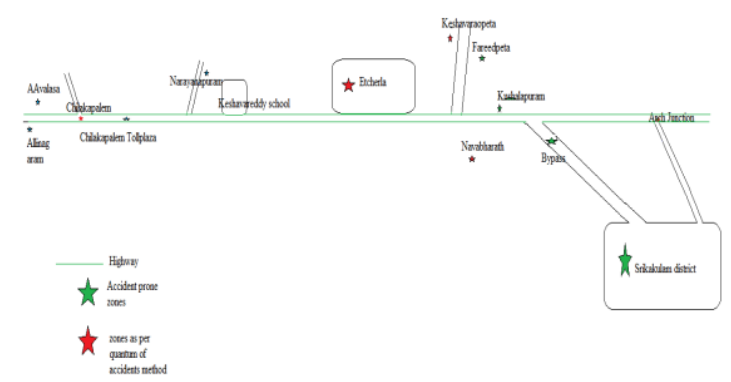

Study area:

Analysing road crash data:

Estimates have shown that 1.24 million road users die every year on the world's roads, and another 20 to 50 million sustain non-fatal injuries as a result of road traffic crashes Traffic safety is a societal issue and all over the world guidelines are made in an attempt to improve traffic safety and thereby decrease the high fatality and injury numbers[5]. Traffic safety is described as the science providing methods (and/or measures) to reduce the number of fatalities and injured road users in traffic accidents

\section{Reporting:}

The issue of under-announcing isn't remarkable to auto collisions and serious underreporting is available in numerous other incident fields[5]. The revealing issues have been tended to in diverse ways[6]: (I) taking a gander at different information sources, (ii) examining social purposes behind detailing, (iii) assessing administration quality inside experts[6].

Srikakulam is a city and the district headquarters of Srikakulam district in the Indian state of Andhra Pradesh. It is a municipal corporation and also the Mandal headquarters of Srikakulam Mandal in Srikakulam revenue division. the city had a population of 2,699,473. National Highway 16 (India), a part of Golden Quadrilateral highway network, bypasses the city.Area20.89Sqkm Population density $7000 / \mathrm{km} 2$
Revised Manuscript Received on July 18, 2019.

K.S.B. Prasad, Assistant Professor, Department of Civil Engineering, GMR Institute of Technology, Rajam - 532127, Andhra Pradesh, India. (E-mail: ksbprasad@gmail.com, prasad.ksb@gmrit.org)

K. Gayatri, P.G Student, Department of Civil Engineering, GMR Institute of Technology, Rajam - 532127, Andhra Pradesh, India. (E-mail: Gayatri.mar28@gmail.com) 


\section{IDENTIFICATION AND PRIORITIZE IMPROVEMENT OF ACCIDENT-PRONE LOCATIONS BETWEEN SRIKAKULAM TO CHILAKAPALEM JUNCTION- A RESEARCH}

Details of accident data collected

1) Date and time of accident

2) Location wise details of accidents

3) Total number of accidents

4) Type of accidents

5) Total number of fatalities and non-fatalities

\section{RESULTS \& DISCUSSIONS}

Table 1 Rate of road accident deaths during

2016 to 2018

\begin{tabular}{|c|c|c|c|}
\hline year & $\begin{array}{c}\text { No, of } \\
\text { Road } \\
\text { accident } \\
\text { Deaths }\end{array}$ & $\begin{array}{c}\text { Estimated } \\
\text { mid-year } \\
\text { Population }\end{array}$ & $\begin{array}{c}\text { Fatality risk } \\
\text { Col2*100/Col3 }\end{array}$ \\
\hline 2016 & 79.6 & 203424 & 39.8 \\
\hline 2017 & 67.9 & 240315 & 28.2 \\
\hline 2018 & 63.6 & 267534 & 23.7 \\
\hline
\end{tabular}

Year wise type of accidents:

Table 2 Type of accidents in the year 2016

\begin{tabular}{|c|c|c|}
\hline Month & Fatal & Non-Fatal \\
\hline Jan & 0 & 2 \\
\hline Feb & 0 & 3 \\
\hline Mar & 0 & 4 \\
\hline Apr & 0 & 3 \\
\hline May & 0 & 2 \\
\hline Jun & 1 & 0 \\
\hline Jul & 1 & 5 \\
\hline Aug & 4 & 7 \\
\hline Sep & 3 & 0 \\
\hline Oct & 0 & 1 \\
\hline Nov & 1 & 5 \\
\hline Dec & 0 & 7 \\
\hline
\end{tabular}

Table 3 Type of accidents in the year 2017

\begin{tabular}{|c|c|c|}
\hline Month & Fatal & Non Fatal \\
\hline Jan & 0 & 3 \\
\hline Feb & 1 & 3 \\
\hline Mar & 1 & 5 \\
\hline Apr & 2 & 4 \\
\hline May & 2 & 7 \\
\hline Jun & 3 & 2 \\
\hline Jul & 0 & 0 \\
\hline Aug & 1 & 6 \\
\hline Sep & 4 & 1 \\
\hline Oct & 0 & 5 \\
\hline Nov & 0 & 0 \\
\hline Dec & 1 & 2 \\
\hline
\end{tabular}

Table 3 Type of accidents in the year 2018

\begin{tabular}{|c|c|c|}
\hline Month & Fatal & Non Fatal \\
\hline Jan & 2 & 2 \\
\hline Feb & 0 & 4 \\
\hline Mar & 1 & 6 \\
\hline Apr & 2 & 3 \\
\hline May & 2 & 2 \\
\hline Jun & 2 & 3 \\
\hline Jul & 0 & 4 \\
\hline
\end{tabular}

\begin{tabular}{|c|l|l|}
\hline Aug & 3 & 2 \\
\hline Sep & 1 & 2 \\
\hline Oct & 2 & 1 \\
\hline Nov & 0 & 2 \\
\hline Dec & 2 & 2 \\
\hline
\end{tabular}

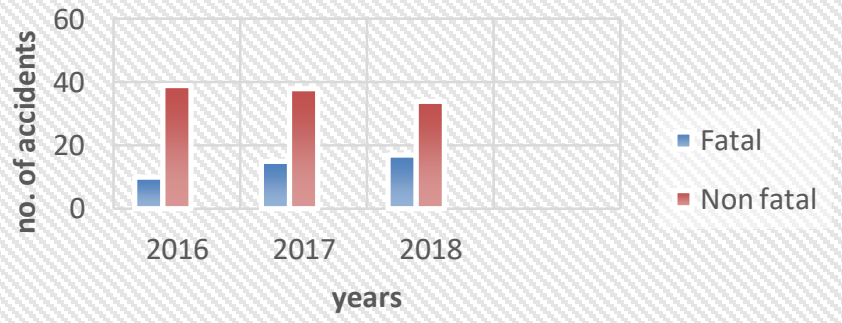

Fig.1-year wise distribution of accidents in Srikakulam

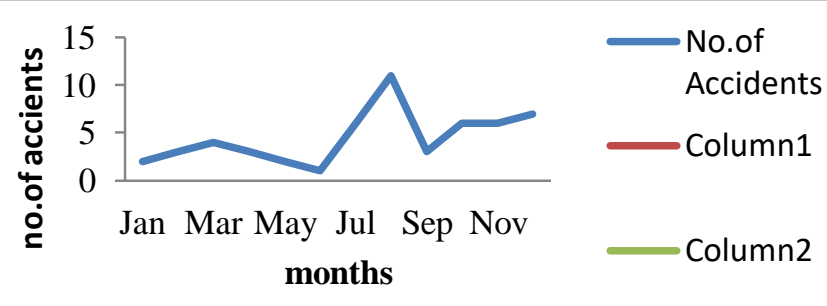

Fig. 2 Month wise distribution of accidents in the year 2016

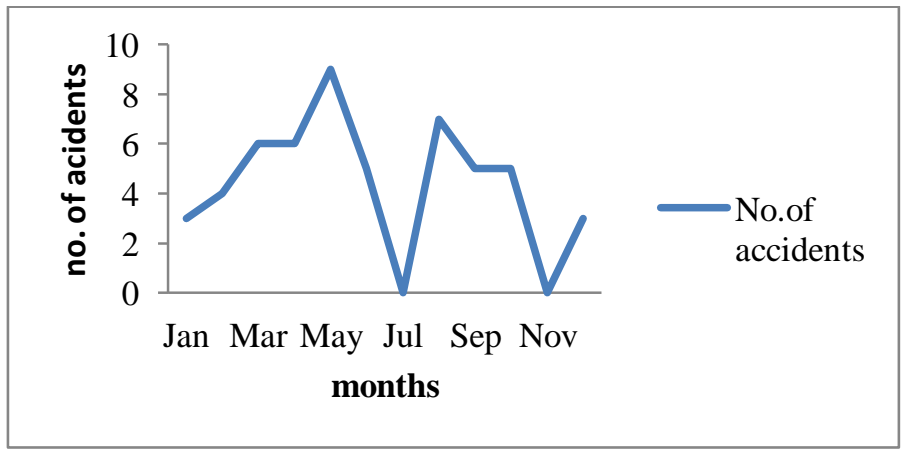

Fig.3 Month wise distribution of accidents in the year 2017

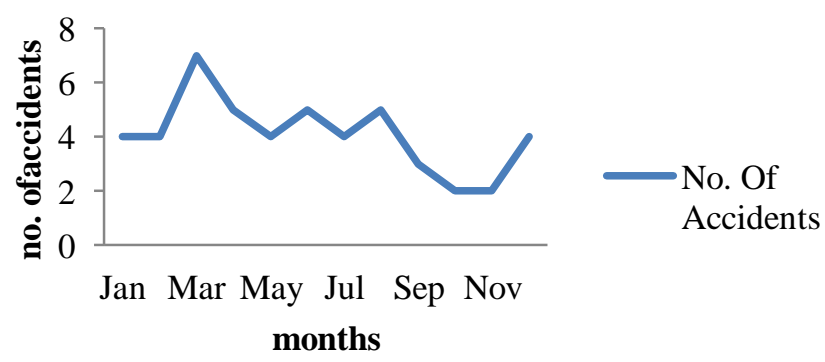

Fig.4 Month wise distribution of accidents in the year 2018

Published By: 
Accident Severity Index Method :(Persons killed for 100 accidents)

Accident severity Index Measures the seriousness of accidents and availability of medical facilities in the city[5]. The below figure shows the severity index shows the number of accidents per 100 accidents.

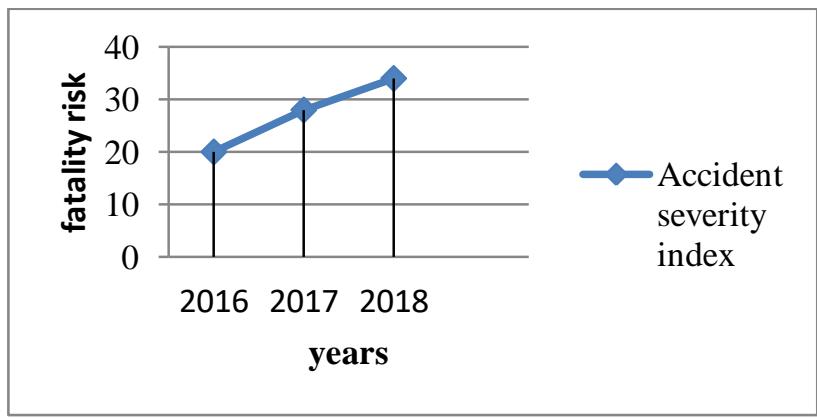

Fig. 5 Fatality risk in three years

Quantum of accident method:

Higher the number of accidents on any stretch, higher would be the accident proneness of the stretch. It has been advanced that two accidents in a year might be because of minor structure surrenders while at least three accidents in a year certainly demonstrate genuine insufficiencies in geometric of road stretch. Along these lines all stretches with at least 9 accidents amid multi year time frame were viewed as accident stretches.

Location wise distribution of accidents in National Highway:

Table 4. Quantum of accident method for Chilakapalem to Srikakulam District

\begin{tabular}{|c|c|c|c|c|}
\hline Location & \multicolumn{2}{|c|}{$\begin{array}{c}\text { No. Of } \\
\text { accidents }\end{array}$} & Total & $\begin{array}{c}\text { Priority for } \\
\text { improvement }\end{array}$ \\
\hline Fatal & $\begin{array}{c}\text { Non- } \\
\text { fatal }\end{array}$ & $\begin{array}{c}\text { Fatal+non- } \\
\text { fatal }\end{array}$ \\
\hline Chilakapalem & 5 & 15 & 20 & 2 \\
\hline Etcherla & 10 & 22 & 32 & 1 \\
\hline Arch Jn & 2 & 10 & 12 & 4 \\
\hline Navabharath Jn & 0 & 10 & 10 & 8 \\
\hline Kesavaraopeta & 3 & 8 & 13 & 3 \\
\hline Jalipinaidupeta & 0 & 3 & 3 & 13 \\
\hline Bypass & 0 & 4 & 4 & 12 \\
\hline Kinthalimill & 3 & 5 & 8 & 6 \\
\hline Kusalipuram & 1 & 2 & 3 & 11 \\
\hline Seepanaidupeta & 1 & 2 & 3 & 11 \\
\hline Thamminaidupeta & 1 & 3 & 4 & 7 \\
\hline Allinagaram & 0 & 8 & 8 & 9 \\
\hline AAvalasa & 4 & 3 & 7 & 5 \\
\hline Fareedpeta & 1 & 3 & 4 & 10 \\
\hline
\end{tabular}

Based on the quantum of accident method priority for 14 locations in the study area were analysed and mentioned in table 4. Priority for the location has marked based on fatal and then total no accidents with both fatal and nonfatal count.

\section{CONCLUSION}

In accident severity method higher rate of accident index is observed as the year increases because of increase in population and vehicles. So, it is an alert that measures like extension of roads with proper road features need to be enhanced. In quantum of accident method locations are analysed based on fatal and then total no accidents with both fatal and nonfatal count. So based on financial resources it is necessary to develop road features based on high prioritize locations in the study stretch.

\section{REFERENCES}

1. Tormo, Maria Teresa; Sanmartin, Jaime and Pace "Update and improvement of the traffic accident data collection procedures in Spain: The METRAS method of sequencing accident events"

2. Farzaneh Moradkhani1, Somayya Ebrahimkhani $\square$ 2, Bahram Sadeghi Begham3 "Road Accident Data Analysis: A Data Mining Approach"

3. Sanjay kumar singh and Ashish Mishra "Road accident data analysis"

4. Gongzhu Hu Liling Li "Analysis of road traffic fatal accidents using data mining techniques"

5. Janstrup, Kira Hyldekær; Kaplan, Sigal; Prato, Carlo Giacomo" Statistical modelling of the frequency and severity of road accidents"

6. Luca Studer 1, Valeria Paglino 1,*, Paolo Gandini 1" Analysis of the Relationship between Road Accidents and Psychophysical State of Drivers through Wearable Devices" 